\title{
ACESSIBILIDADE DIGITAL EM SISTEMAS ACADÊMICOS DA UFPB: ANÁLISE A PARTIR DAS HEURÍSTICAS DE USABILIDADE
}

\section{DIGITAL ACCESSIBILITY IN ACADEMIC SYSTEMS AT UFPB: ANALYZE FROM USABILITY HEURISTICS}

\author{
Ilka Maria Soares Camposa \\ Eliane Bezerra Paivab \\ Ronnie Anderson Nascimento de Fariasc
}

\begin{abstract}
RESUMO
Introdução: A relação digital e acessibilidade perpassa o universo das tecnologias, que por sua vez envolve uma evolução que se amplia a todo instante com recursos que podem construir aproximações e/ou distanciamentos. Objetivo: $O$ estudo objetiva analisar a acessibilidade digital em sistemas acadêmicos da Universidade Federal da Paraíba (UFPB) a partir das heurísticas de usabilidade. Metodologia: a pesquisa caracteriza-se como exploratória e de natureza qualitativa. Como instrumento de coleta de dados adotou-se uma entrevista semiestruturada que foi aplicada aos discentes da UFPB que fazem parte do Comitê de Inclusão e Acessibilidade da Universidade Federal da Paraíba e docentes que possuem alguma deficiência. Para análise dos dados, utilizou-se a técnica de análise de conteúdo de Bardin. Resultados: Os resultados da pesquisa demonstraram um alto índice de insatisfação dos usuários com a utilização dos sistemas nos aspectos que envolvem a "liberdade de controle fácil para o usuário", "flexibilidade e eficiência de uso" e "correspondência entre o sistema e o mundo real" que correspondem a fatores de grandes barreiras digitais, com ênfase na ausência de uma linguagem comum e interface inadequada. Conclusão: Conclui-se, então, que os portais acadêmicos da UFPB não oferecem acessibilidade e apresentam barreiras digitais comprometendo a vida acadêmica de discentes e docentes nas suas necessidades de informação.
\end{abstract}

Descritores: Acessibilidade digital. Sistemas Acadêmicos. Usabilidade. Barreiras à informação. Usuário da informação.

a Doutoranda do Programa de Pós-Graduação em Ciência da Informação da Universidade Federal da Paraíba (PPGCI-UFPB). E-mail: ik.campos@uol.com.br

b Docente do Departamento de Ciência da Informação e Programa de Pós-Graduação em Ciência da Informação da Universidade Federal da Paraíba (PPGCI-UFPB). E-mail: paivaeb@gmail.com

c Doutorando do Programa de Pós-Graduação em Ciência da Informação da Universidade Federal da Paraíba (PPGCI-UFPB). E-mail: ronnieufrn@yahoo.com 


\section{INTRODUÇÃO}

A acessibilidade digital, - um tema que necessita de reflexões - possui desafios diante de barreiras, às vezes, explícitas ou não para os usuários da informação. As reivindicações, neste contexto são muitas, mas ainda caminham a passos lentos em direção a soluções para eliminar ou minimizar as barreiras existentes no processo de inclusão digital. De acordo com Saracevic (1996, p. 43),

[...] uma vez que a ciência e a tecnologia são críticas para a sociedade (por exemplo, para a economia, saúde, comércio, defesa) é também crítico prover os meios para o fornecimento de informações relevantes para indivíduos, grupos e organizações envolvidas com a ciência e a tecnologia, já que a informação é um dos mais importantes insumos para se atingir e sustentar o desenvolvimento em tais áreas.

É preciso um olhar crítico para a relação digital e acessibilidade que perpassa o universo das tecnologias, que por sua vez envolve uma evolução que se amplia a todo instante com recursos que podem construir aproximações e/ou distanciamentos. Refletir nesse viés envolve pensar na inclusão social que deve estar contida na inclusão digital. Logo, é preciso direcionar para que as diversidades estejam sendo contempladas e respeitadas para que a acessibilidade ocorra e naturalmente a usabilidade se concretize sem distinção.

Nessa perspectiva, percebe-se que determinados usuários da informação podem se deparar com barreiras de acessibilidade digital como limitações no uso dos sistemas acadêmicos quando, para resolverem uma necessidade informacional, realizam pesquisas científicas, cursos virtuais, videoconferência, interatividade, dentre outros. Aspectos como geográfico, social, financeiro também refletem restrições nas inúmeras possibilidades que poderiam existir para todos.

As barreiras da acessibilidade digital para os usuários de sistemas acadêmicos estão relacionadas à sua usabilidade que, de acordo com Nielsen (1994), envolvem atributos que vão desde a facilidade de aprender, eficiência de uso, facilidade de relembrar a forma do último acesso, evitar erros, assim como a satisfação diante do sistema. Considerando esse contexto, questiona-se: como 
se configura a acessibilidade digital em sistemas acadêmicos na UFPB? Quais as barreiras à acessibilidade digital dos usuários da informação em sistemas acadêmicos na UFPB? Buscando encontrar resposta para tais questionamento realizou-se uma pesquisa que teve como objetivo: Analisar a acessibilidade digital em sistemas acadêmicos na UFPB a partir das heurísticas de usabilidade. Analisar as barreiras à acessibilidade digital dos usuários da informação em sistemas acadêmicos na UFPB.

Para atingir tal objetivo, desenvolveram-se os seguintes objetivos específicos: a) traçar o perfil dos usuários da informação do CIA/UFPB; b) identificar e descrever barreiras à acessibilidade digital dos usuários da informação em sistemas acadêmicos; c) apresentar sugestões e melhorias da acessibilidade dos usuários da informação nos sistemas acadêmicos.

O presente trabalho é um relato de uma pesquisa cuja sua justificativa se deu pela preocupação com as barreiras que podem existir na acessibilidade digital aos sistemas acadêmicos.

\section{USUÁRIO DA INFORMAÇÃO}

Os usuários de informação têm como propósito a busca de informação para sanar alguma necessidade. Em alguns momentos eles podem se deparar com determinadas situações que são geradas por barreiras digitais à acessibilidade. Essas dificuldades podem estar inseridas em estruturas de ambientes de busca para criação ou disseminação da informação que não refletem um espaço de inclusão para todos, sem especificidades de recursos que atendam todas as necessidades.

Os usuários com necessidades especiais e de acessibilidade são acobertados pela lei Federal oㅜ 13.146, de 6 de julho de 2015 que visa à sua inclusão social, cidadania, garante acesso à educação superior, profissional e tecnológica em igualdade de oportunidades. Dessa forma,

Art. 2 o Considera-se pessoa com deficiência aquela que tem impedimento de longo prazo de natureza física, mental, intelectual ou sensorial, o qual, em interação com uma ou mais barreiras, pode obstruir sua participação plena e efetiva na sociedade em igualdade de condições com as demais pessoas 
(BRASIL, 2015, não paginado).

A lei ainda garante 0 acesso às informações e disponibilização de recursos de comunicação acessíveis, como no art. 63 a qual é "obrigatória a acessibilidade nos sítios da internet mantidos por empresas com sede ou representação comercial no país ou por órgãos de governo" (BRASIL, 2015, não paginado) para uso dos usuários especiais, conforme as melhores práticas e diretrizes de acessibilidade adotadas internacionalmente.

Associado a essa inclusão tem o termo acessibilidade que configura a possibilidade e condição de alcance, percepção e entendimento para utilização, com segurança e autonomia de pessoas com deficiência, aos sistemas e tecnologias proporcionada pelos sites (ABNT, 2015).

Estudar questões relacionadas à acessibilidade e usabilidade em ambientes digitais vai além dos estudos de questões técnicas necessárias para o desenvolvimento de sistemas e/ou interfaces. Faz-se necessário expandir os limites técnicos e contemplar pontos cognitivos e comportamentais dos usuários na busca do entendimento sobre quais elementos podem impactar o acesso e uso dessas tecnologias por parte de seus usuários.

É preciso entender que as tecnologias podem impactar os usuários nos contextos que envolvem limitações digitais. Logo, elas podem ser entendidas como sendo uma abordagem baseada na "exclusão digital" ou "desigualdade digital". Bellini et al. (2012) considera que as limitações digitais buscam estudar a relação entre o indivíduo e a tecnologia, não se restringindo apenas ao fato deste indivíduo (ou o seu grupo) possuir ou não possuir acesso à mesma. Ainda segundo o referido autor, na área das limitações digitais, são explorados elementos relativos à cognição e ao comportamento tecnológico do indivíduo.

O estudo do impacto da presença de TICs - Tecnologias de Informação e Comunicação - para discentes portadores de necessidades especiais se torna insuficiente quando se analisa apenas o elemento acesso a recursos de TICs. É possível perceber que outras questões geram influência nos referidos usuários, mesmo esses atuando em ambientes com possibilidade de acesso a diversos recursos tecnológicos. Para esses casos, elementos comportamentais e cognitivos exercem influência e devem ser analisados com maior atenção. 
Bellini et al. (2012) comentam que as limitações digitais podem ser divididas em limitações de acesso, cognitivo-informacional e comportamentais. Segundo este autor:

Limitações de acesso (LA), que se referem a dificuldades sociais e materiais de um indivíduo para acessar as tecnologias de informação e comunicação (TICs), resultando de restrições econômicas, falta de acesso voluntário, inadequação dos recursos tecnológicos disponíveis, interfaces homem-máquina de baixa ergonomia, ambientes de uso insalubres e outros fatores;

Limitações cognitivo-informacionais (LI), que se referem a dificuldades de um indivíduo relativas às habilidades de fazer uso efetivo das TICs, podendo se manifestar no saber buscar, selecionar, processar e aplicar informações em meios digitais; e

Limitações comportamentais (LC), que se referem a dificuldades de um indivíduo para aplicar plenamente suas habilidades digitais, mesmo que as possua em nível elevado, em função de vício em determinadas informações, apatia funcional e outros fatores (BELLINI et al., 2012, p. 59, grifos dos autores).

Considera-se, em um primeiro momento, que existe uma relevância maior das limitações digitais definidas como limitações de acesso e limitações cognitivo-informacionais. É oportuno mencionar que limitações de acesso não se resumem apenas ao fato de o usuário ter ou não acesso físico às ferramentas de TICs (BELLINI et al., 2012), mas as condições que os portais devem disponibilizar que a usabilidade e a encontrabilidade, de fato, ocorram para os usuários.

O estudo das limitações digitais restrito apenas às limitações de acesso e às limitações cognitivo-informacionais pode apresentar resultados incompletos ou equivocados para a identificação e compreensão dos elementos que exercem influência negativa na utilização de portais acadêmicos por parte de usuários portadores de necessidades especiais. Nenhum processo informacional acontece sem dificuldades. No processo de busca da informação muitas vezes o usuário se depara com desvios que dificultam, atrasam ou bloqueiam a obtenção da informação, comprometendo a eficácia do processo de transferência e consequente uso da informação. A essas dificuldades dá-se o nome de obstáculos e/ou barreiras informacionais.

Em um processo informacional algumas limitações digitais são 
encontradas e os usuários se veem diante de barreiras que impossibilitam a aquisição de informação que podem estar relacionadas, de acordo com Figueiredo (1999), a questões como: demora no tempo; excesso de informação; informação com capacidade inferior; dispersão de informação em canais diferentes; literatura não convencional; restrições de informação; estratégia de busca fácil; barreiras de língua estrangeira; restrições de tempo; isolamento geográfico; por fim, terminologia e atraso na biblioteca. Da mesma forma, a própria estrutura com ausência de um padrão de publicação com manutenção dos sistemas pode causar demora na atualização das informações, assim como sua qualidade e seu excesso.

Para Guinchat e Menou (1994) alguns obstáculos surgem e comprometem a comunicação como: de institucionais, financeiros, linguísticos e psicológicos. A falta de linguagem que contemple todos os públicos de usuários corresponde a outro fator de grande relevância na limitação digital.

Nessa perspectiva, no que se refere à identificação e compreensão das limitações digitais existentes no acesso a portais acadêmicos, por parte dos usuários portadores de necessidades especiais, foram levados em consideração elementos presentes nas limitações digitais de acesso cognitivo-informacionais e comportamentais para analisar os resultados da pesquisa. Isso possibilitou uma análise mais completa do cenário estudado fornecendo resultados com melhor qualidade.

Faz-se necessário evidenciar que no estudo de usuários as necessidades se relacionam com os parâmetros que promovem a usabilidade dos sistemas. Choo (2003, p. 118) considera que "as necessidades de informação não surgem plenamente formadas, mas são clarificadas e definidas durante um período de tempo". Assim, a necessidade de informação do usuário pode ser contemplada a partir do momento que ele poderá dar significado ao contexto que ele está buscando. Entretanto, é preciso que os meios para sua busca, acessibilidade e usabilidade possam ser possíveis para atender sua necessidade. Para Barros, Saorim e Ramalho (2008, p. 174) a necessidade de informação "consiste numa percepção de um vazio cognitivo em que perpassam sentimentos de incertezas, dúvidas, angústias e todo tipo de manifestação que poderá ou não canalizar 
forças no indivíduo para transpor tal situação".

\section{USABILIDADE}

Conforme Nielsen (1994), a usabilidade é um processo de avaliação heurística realizado com uma verificação por especialistas na interface do sistema disponibilizado ao usuário em busca de verificar sua adequação eficaz. É aconselhável, por segurança da neutralidade de resultado, que esse procedimento seja realizado individualmente por mais de uma pessoa. Os atributos para verificação da usabilidade de acordo com Nielsen (1994, p. 16) são:

a) Facilidade de aprender: O sistema deve ser fácil de aprender, para que um usuário possa concluir uma tarefa rapidamente e sem dificuldades. A interface deve ser clara e objetiva;

b) Eficiência de uso: O sistema deve ser eficiente na tarefa que se propõe a realizar. O usuário deve atingir um alto nível de produtividade;

c) Memorização: As funcionalidades do sistema devem ser fáceis de relembrar, mesmo após o usuário ficar certo período de tempo sem usá-lo, sem necessidade de um novo treinamento;

d) Poucos Erros: O sistema deve produzir um número de erros reduzido e se um erro ocorrer, o usuário deve poder resolvê-lo ou ignorá-lo de forma rápida e simples;

e) Satisfação: E a percepção do usuário diante da interface do sistema. A interface deve ser agradável e o usuário deve se sentir satisfeito e gostar de usar o sistema. Essa medida é totalmente subjetiva.

Considerando todos os atributos apresentados pelo autor, faz-se necessário pensar que para uma usabilidade o layout dos sistemas, ou seja, a interface precisa dispor de elementos facilitadores para interação com os usuários, quando se pensa que a mesma tem a função de interligar operações e atender às necessidades de uso. Sua estrutura precisa permitir uma integração de opções de recursos e serviços de forma clara para os usuários. Assim, podese pensar em um ambiente interativo.

A usabilidade de um sistema precisa ser monitorada para que os fatores que podem impedir o sucesso de seu funcionamento possam ser corrigidos. 
Ferreira (2007, p. 52) aponta que uma avaliação de usabilidade, "consiste em qualquer estudo de natureza analítica ou empírica de um sistema, cuja meta de avaliação e fornecer um diagnóstico do sistema avaliado". Para acompanhar a usabilidade de interfaces com os usuários, Queiroz (2001) elenca alguns instrumentos podem ser empregados, tais como: observações, questionamentos, entrevistas, captura de tela de forma automática, debates em grupos, feeedback de usuários, dentre outros.

Nesse viés, percebe-se que a usabilidade pode ser monitorada com avaliações contínuas a fim de obter um melhor uso pelos usuários. Barbosa (2009) considera que monitoramento poderá trazer benefícios nos aspectos que envolvem a diminuição de falhas e suporte, ampliação de uso, dentre outros. Nos aspectos que envolvem os problemas de usabilidade dos sistemas para com os usuários, tanto as barreiras digitais como os obstáculos estão inseridos como fatores que impedem uma eficiência no desempenho de interação e de uso. Para tanto, Nielsen (1994) recomenda para essas dificuldades dez heurísticas (Quadro 1).

\section{Quadro 1 - Dez Heurísticas de Nielsen (1994)}

\begin{tabular}{|l|l|}
\hline \multicolumn{1}{|c|}{ HEURÍSTICAS } & \multicolumn{1}{c|}{ FINALIDADE } \\
\hline $\begin{array}{l}\text { 1. Visibilidade do estado do } \\
\text { sistema }\end{array}$ & $\begin{array}{l}\text { o sistema deve manter os usuários informados do } \\
\text { que está acontecendo a cada momento. }\end{array}$ \\
\hline $\begin{array}{l}\text { 2. Correspondência entre o } \\
\text { sistema e o mundo real }\end{array}$ & $\begin{array}{l}\text { o sistema deve falar a linguagem do usuário, com } \\
\text { palavras, frases e conceitos que sejam familiares } \\
\text { para ele, em lugar de termos técnicos orientados ao } \\
\text { próprio sistema. }\end{array}$ \\
\hline $\begin{array}{l}\text { 3. Liberdade e controle por } \\
\text { parte do usuário }\end{array}$ & $\begin{array}{l}\text { com alguma frequência, os usuários escolhem } \\
\text { funções do sistema por engano, deve ser } \\
\text { oferecida uma "saída de emergência", claramente } \\
\text { sinalizada, para que possam sair do estado } \\
\text { indesejado. }\end{array}$ \\
\hline 4. Consistência e padrões & $\begin{array}{l}\text { devem ser seguidas convenções para que os } \\
\text { usuários não tenham que se perguntar se palavras, } \\
\text { situações ou ações significam, de fato, a mesma } \\
\text { coisa. }\end{array}$ \\
\hline 5. Prevenção de erros & $\begin{array}{l}\text { preferível a ter boas mensagens de erro é ter um } \\
\text { design que evite a ocorrência de problemas. }\end{array}$ \\
\hline
\end{tabular}




\begin{tabular}{|l|l|}
\hline $\begin{array}{l}\text { 6. Reconhecimento } \\
\text { preferível à memorização }\end{array}$ & $\begin{array}{l}\text { o sistema deve minimizar a quantidade de } \\
\text { informação que o usuário precisará lembrar para } \\
\text { usá-lo, fazendo com que objetos, ações e opções } \\
\text { sejam visíveis. }\end{array}$ \\
\hline $\begin{array}{l}\text { 7. Flexibilidade e eficiência } \\
\text { de uso }\end{array}$ & $\begin{array}{l}\text { os aceleradores, invisíveis para o usuário } \\
\text { inexperiente, podem agilizar a interação para o } \\
\text { usuário experiente, de forma que o sistema possa } \\
\text { atender aos dois perfis de utilizadores. }\end{array}$ \\
\hline $\begin{array}{l}\text { 8. Design estético e } \\
\text { minimalista }\end{array}$ & $\begin{array}{l}\text { os diálogos não devem conter informações } \\
\text { irrelevantes ou muito raramente requisitadas. }\end{array}$ \\
\hline $\begin{array}{l}\text { 9. Ajuda aos usuários para } \\
\text { reconhecer, diagnosticar e } \\
\text { se recuperar dos erros }\end{array}$ & $\begin{array}{l}\text { as mensagens de erro devem ser expressas em } \\
\text { linguagem compreensível (sem códigos). }\end{array}$ \\
\hline $\begin{array}{l}\text { 10. Suporte e documentação } \\
\text { é preferível que o sistema possa ser usado sem } \\
\text { documentação, mas pode resultar necessário } \\
\text { fornecer suporte e documentação ao usuário. }\end{array}$ \\
\hline
\end{tabular}

Fonte: Dez Heurísticas de Nielsen (1994).

As recomendações nas dez heurísticas de Nielsen (1994), apresentadas no Quadro 1, descrevem orientações que deveriam estar contidas em todos os sistemas para que barreiras sejam evitadas e a acessibilidade digital ocorra de forma plena e eficaz.

\section{ACESSIBILIDADE DIGITAL}

Entre as décadas de 1940 e 1960, o termo acessibilidade aplica-se diretamente a questões físicas e funcionais. Entretanto, a partir da década de 1980, estimulado pelo Ano Internacional das Pessoas Deficientes (1981), a questão da acessibilidade e eliminação de barreiras arquitetônicas ganha relevância no cenário internacional e se transforma em metas para as nações desenvolvidas e em desenvolvimento (PASSERINO; MONTARDO, 2007).

Passerino e Montardo (2007) referem que, a partir dos anos de 1990, com a popularização da Internet e de comunidades virtuais nos Estados Unidos, surge a necessidade de prover esse acesso universal na web por meio da construção de ambientes virtuais acessíveis. Assim, dois consórcios, o W3C (Consórcio para a Web) e a WAI (Iniciativa para a Acessibilidade na Rede), 
estabelecem padrões e protocolos a serem seguidos, contribuindo para a popularização do termo acessibilidade.

A acessibilidade na web em seu conceito básico inclui usuários em websites ou sistemas para que todas as pessoas consigam utilizá-los, independentemente se possui ou não alguma deficiência, por isso um site que permita seu fácil uso a todos usuários precisa levar em consideração os conceitos de usabilidade e acessibilidade (FUCUSHIMA; MARQUES; PARRÃO, 2020).

Na programação dos portais/sites devem ser levados em consideração: a disponibilidade de atalhos para a navegação, disponibilidade na descrição de imagens, mensagens de erros e como solucioná-los de modo eficaz, evitar usar cores muito fortes no layout e entre outros cuidados que o desenvolvedor deve pensar durante o desenvolvimento da programação e até mesmo em aparelhos físicos (FUCUSHIMA; MARQUES; PARRÃO, 2020, p. 10).

As páginas web devem ser desenvolvidas de forma eficaz para evitar as barreiras encontradas por usuários com ou sem deficiência. A acessibilidade tem a mesma qualidade da interação da usabilidade com os sistemas de informação, produto ou serviço, mas com ampla diversidade de usuário alçado, de acordo com as definições das ISO 9241-11 (1998) e ISO 9241-171(2008). (SOUZA, 2016). Ela permite que todos tenham acesso aos recursos que transmitem educação, trabalho, informação, dentre outras coisas que os usuários necessitam na sua vida cotidiana universitária. (SANTOS et al., 2018).

As heurísticas de Nielsen (1994) permitem um aperfeiçoamento dos recursos informacionais digitais pela eliminação das barreiras à acessibilidade digital e uma maior usabilidade nos ambientes informacionais. A usabilidade permeia todos as heurísticas listadas no Quadro 1 e pode favorecer a satisfação das necessidades informacionais dos usuários. Essas heurísticas são um método de avaliação com foco na interface de uso do usuário e em sua usabilidade e se for unido aos atributos de acessibilidade fornecem elementos e subsídios para ambientes digitais que facilitam a interação com os usuários (VIDOTTI et al., 2017).

A Acessibilidade é a possibilidade de transpor as barreiras analógicas e 
digitais para que a qualidade de vida e inclusão social de pessoas com deficiência sejam igualitárias; ela inclui o uso de tecnologias assistivas e adoção de desenho universal para que a independência da sua necessidade não se depare com as barreiras apresentadas diante das suas capacidades físicomotoras e perceptivas, culturais e sociais., seja em locais, produtos, serviços ou informações, metodologias, técnicas entre outros (HOTT; CRUZ-RIASCO, 2018).

O acesso à informação é um direito de uma sociedade democrática e para isso, a web se faz presente em muitos aspectos da vida: educação, emprego, governo, comércio, saúde, recreação etc. Conforme Henry (2019, não paginado), "it is essential that the Web be accessible in order to provide equal access and equal opportunity to people with diverse abilities'. Com isso, o acesso aos recursos que proporcionem tecnologias de informação e comunicação é um direito básico humano e deve ser exercido pelos órgãos governamentais.

\section{PERCURSO METODOLÓGICO}

Os procedimentos metodológicos desta pesquisa foram norteados por uma abordagem exploratória, porque é um primeiro estudo na UFPB voltado à acessibilidade de seus portais. Sua natureza é qualitativa com intuito de analisar as barreiras à acessibilidade digital dos usuários da informação em sistemas acadêmicos. O universo da pesquisa corresponde aos discentes que fazem parte do Comitê de Inclusão e Acessibilidade (CIA) e docentes que perceberam alguma barreira digital no Portal da Universidade Federal da Paraíba-UFPB, Campus I.

Esta pesquisa também é do tipo estudo de caso e consiste em "coletar e analisar informações sobre determinado indivíduo, uma família, um grupo ou uma comunidade, a fim de estudar aspectos variados de sua vida, de acordo com o assunto da pesquisa" (PRODANOV; FREITAS, 2013, p. 60). Para os autores, a pesquisa pode ser qualitativa e/ou quantitativa por meio de uma

\footnotetext{
1 Tradução nossa: "é essencial que a Web seja acessível para fornecer acesso igual e oportunidades iguais a pessoas com habilidades diversas".
} 
investigação aprofundada de um objeto de uma unidade com sujeito, grupo ou comunidades.

O campo da Pesquisa é o Portal da Universidade Federal da Paraíba UFPB. Ele tem o padrão acessível em suas páginas que permite: alterar o tamanho da fonte, fazer o contraste da tela de apresentação e a associação de teclas - que remete o usuário ao mapa do site, tela principal e página de acessibilidade. Essas ferramentas estão disponíveis em todas as páginas do portal (UFPB, 2018) e foram avaliadas na discussão pelo software ASES - O Avaliador e Simulador de Acessibilidade em Sítios (ASES) - uma ferramenta desenvolvida pelo eMAG para avaliar a acessibilidade de páginas da web e garantir aos usuários uma página de fácil uso e aos seus desenvolvedores as recomendações do eMAG (BRASIL, 2014).

A quantificação dos alunos com necessidades especiais na UFPB foi realizada pelo INEP - Instituto Nacional de Estudos e Pesquisas Educacionais Anísio Teixeira. O Censo de 2017 da Educação Superior na Paraíba apresentou os discentes e portadores de deficiência na UFPB um total de 871 deficientes sendo: 24 - cegueira, 523 - baixa visão, 37- surdez, 86 - deficiência auditiva, 189 - deficiência física e 12- deficiência múltipla.

Diante dessa demanda e da necessidade do acolhimento dos discentes deficientes foi instituído oficialmente no dia 26 de novembro de 2013 - através da Resolução no 34/2013 do Conselho Universitário (CONSUNI) - o Comitê de Inclusão e Acessibilidade (CIA) da UFPB. Ele é uma assessoria especial vinculada diretamente ao Gabinete da Reitoria e é o único no país até então (UFPB, 2018).

Outro órgão é o Núcleo de Educação Especial (NEDESP) tem sua subordinação no Centro de Educação (CE). De acordo com os dados sobre o órgão contidos no portal da UFPB/NEDESP, suas responsabilidades são voltadas para a adaptação, a transcrição e revisão de textos e obras acadêmicas de tinta para o sistema Braille - e vice-versa. Os recursos usados são manuais a tecnologias assistivas: softwares de reconhecimento de texto, scanner ledor, ledores de tela e impressoras Braille. A média atendida não supera trinta alunos cegos, surdocegos e de baixa visão matriculados no Campus I da UFPB, em 
João Pessoa, nos diversos cursos de graduação e pós-graduação (UFPB, 2018).

Para proporcionar os portais da UFPB acessíveis foram adotadas recomendações internacionais do WCAG (World Content Accessibility Guide) do W3C, as quais foram adaptadas pelo Governo Brasileiro na figura do eMAG (Modelo de Acessibilidade em Governo Eletrônico) para os sites do governo. $O$ governo federal, pelo eMAG, preconiza padrões que devem estar presentes nos sites acessíveis, que são: 1 . Teclas de atalho; 2 . Primeira folha de contraste; 3. Barra de acessibilidade; 4. Apresentação do mapa do sítio; 5. Página com a descrição dos recursos de acessibilidade (BRASIL, 2014, não paginado). Considerando as recomendações internacionais WCAG, anteriormente mencionadas, esses recursos que seguem padrões para acessibilidades devem estar presentes em todos os sites para evitar certas barreiras.

Para a coleta de dados realizou-se uma entrevista semiestruturada com seis sujeitos, sendo três professores e três alunos. Como recursos foram adotados um gravador e um diário de campo, a fim de se registrar as falas dos entrevistados. $O$ incidente crítico foi também uma técnica utilizada na pesquisa a fim de se identificar o último momento em que o entrevistado vivenciou ao buscar informação em um sistema acadêmico. Para Flanagan (1973, p. 100), o incidente crítico é "qualquer atividade humana observável que seja completa em si mesma para permitir inferências e previsões a respeito da pessoa que executa o ato".

$\mathrm{Na}$ análise dos dados utilizou-se a análise de conteúdo "técnica que consiste em descobrir os 'núcleos de sentido' que compõem a comunicação e cuja presença ou frequência de aparição podem significar alguma coisa para o objetivo analítico estudado" (BARDIN, 2016, p. 135). De acordo com o autor, em um processo de análise de dados faz-se necessário a criação de categorias para que se possa realizar um olhar de forma selecionada em grupos de respostas. O processo de categorização baseou-se nas heurísticas de Nielsen (1994). Na pré-análise realizou-se a transcrição das entrevistas e a sua posterior leitura. A exploração do material correspondeu à análise das entrevistas. $O$ tratamento dos resultados correspondeu à interpretação dos dados à luz das entrevistas 
realizadas, inferências dos resultados baseadas nas heurísticas de Nielsen (1994), conforme serão apresentadas no próximo tópico.

\section{RESULTADOS DA PESQUISA}

Este tópico corresponde aos resultados obtidos na pesquisa, onde serão apresentadas a caracterização do usuário da informação e as categorias analisadas a partir das heurísticas de Nielsen (1994): correspondência entre o sistema e o mundo real, usabilidade dos sistemas acadêmicos e consistência e padrões, prevenção de erros, ajuda os usuários a reconhecerem, diagnosticarem e recuperarem-se de erros, ajuda e documentação.

\subsection{CARACTERIZAÇÃo do USUÁRIO da INFORMAÇÃo}

A fim de manter o sigilo, preservando a identidade dos entrevistados, procedeu-se à sua codificação; foram todos denominados pela letra "E" seguida de um número de 1 a 6 , correspondendo ao total de sujeitos que participaram da pesquisa. Os entrevistados (E1 a.E6) serão citados durante toda a análise dos dados.

Um dado importante coletado por meio de um intérprete da Comissão de Inclusão e Acessibilidade (CIA) da UFPB é que existem apenas três discentes em toda a UFPB com surdez completa com vínculo no CIA. Entretanto, como o estudo se deu no Campus I, essas pessoas citadas se encontram em outros campi. Realizou-se, inicialmente, uma pequena caracterização de cada sujeito, conforme segue a Tabela 1:

Tabela 1 - Caracterização dos sujeitos da pesquisa

\begin{tabular}{l|c|c|c|c|c|c}
\hline USUÁRIO & E1 & E2 & E3 & E4 & E5 & E6 \\
\hline Gênero & $\mathrm{M}$ & $\mathrm{F}$ & $\mathrm{F}$ & $\mathrm{F}$ & $\mathrm{M}$ & $\mathrm{M}$ \\
\hline Idade & 27 & 35 & 37 & - & - & - \\
\hline $\begin{array}{l}\text { Formação } \\
\text { Acadêmica }\end{array}$ & $\mathrm{PED}$ & $\begin{array}{c}\text { Mestranda } \\
\text { em gestão } \\
\text { publica }\end{array}$ & $\begin{array}{c}\text { Doutor. } \\
\text { em Letras }\end{array}$ & Radialista & $\mathrm{PED}$ & $\begin{array}{c}\text { Ms. } \\
\text { Letras }\end{array}$ \\
\hline $\begin{array}{l}\text { Discente (Di) ou } \\
\text { Docente (Do) }\end{array}$ & $\mathrm{Di}$ & $\mathrm{Di}$ & $\mathrm{Do}$ & $\mathrm{Di}$ & $\mathrm{Di}$ & $\mathrm{Do}$ \\
\hline Assistência estudantil & $\mathrm{Sim}$ & $\mathrm{Não}$ & $\mathrm{Não}$ & $\mathrm{Sim}$ & $\mathrm{Sim}$ & Não \\
\hline
\end{tabular}




\begin{tabular}{l|c|c|c|c|c|c}
\hline $\begin{array}{l}\text { Tipo de } \\
\text { Deficiência }\end{array}$ & Visão & Física & $\begin{array}{c}\text { surdez } \\
\text { completa }\end{array}$ & Visão & visão & $\begin{array}{c}\text { surdez } \\
\text { completa }\end{array}$ \\
\hline $\begin{array}{l}\text { Nível de } \\
\text { Deficiência }\end{array}$ & Baixa & Congênita & Congênita & Congênita & Baixa & congênita \\
\hline Tempo de deficiência & 8 anos & 35 & 37 & - & - & - \\
\hline
\end{tabular}

Fonte: Dados da pesquisa (2018)

A proporção do número de homens $(\mathrm{M})$ em relação as mulheres $(\mathrm{F})$ nas entrevistas foi a mesma. Entretanto, a formação acadêmica possuiu uma variação de cursos com pedagogia, radialista e letras. No que concerne ao tipo de deficiência, a visão apresentou um número maior em relação aos demais elencados pelos entrevistados. Nesse aspecto, se fez observar que, independente dos entrevistados, existe uma diversidade e particularidade com suas necessidades de acordo com cada nível de deficiência.

De acordo com a Tabela 1, alguns sujeitos não informaram dados como idade e tempo de deficiência. Essas lacunas nas respostas da caracterização dos sujeitos não alteram e nem comprometem os resultados da pesquisa.

\subsection{Categoria 1 - CorrespondênCia entre o Sistema e o Mundo Real}

Considerando os entrevistados, percebeu-se que, em sua maioria, na busca de informações os recursos que eles sentiram falta se relacionam com o portal acadêmico SIGAA. De acordo com E1 não se encontra dentro da realidade deles e não tem condições de uso. De forma explícita, o E4 expõe: "os sistemas não têm correspondência com o nosso mundo real. Todos os dias que estou na UFPB preciso utilizar o SIGAA para obter ou acompanhar conteúdos postados pelos professores e não tenho condições de usar". Na mesma linha de resposta, seguiram os entrevistados, E2, E3, E5 e E6.

O E5 relatou que até tentou algumas vezes acessar o portal UFPB pelo celular, mas não foi possível diante das dificuldades de acessibilidade total com telas pequenas e sem nenhum recurso. Outros sistemas também foram citados pelos entrevistados como o Portal da UFPB, Portal da biblioteca e repositório BDTD, diante da ausência de recursos nos sistemas para busca de informações documentais. Em contraponto o E2, que possui limitações físicas relatou que acessa mais via celular, porém, às tecnologias não condizem com a realidade 
de acesso para pequenas telas. Logo, percebe-se uma ausência de relação com o mundo real dos usuários entrevistados. Para Nielsen (1994), deve haver um importante relacionamento entre os sistemas na proximidade com o mundo real dos usuários, dando condições de uso através de uma estrutura lógica e comum.

Para o E2, cadeirante, os sites favorecem porque não há necessidade de deslocamento para busca de informação. Ele usa os serviços virtuais da UFPB para resolução de sua busca de informação e tem sucesso, apesar das dificuldades identificadas na interface. Já o E1, relata que: "Sim. Existe uma semelhança com o mundo real, economiza o tempo e as barreiras do mundo real, diante de suas limitações".

Nesse viés, o site da biblioteca e o catálogo digital facilitam a procura por livros na Biblioteca Central da UFPB, mas muitas vezes precisa da ajuda do aluno ledor para entender o funcionamento do site, como por exemplo, o SIGAA. O E3 relata a falta de capacitação para usar o SIGAA, o que se tornaria uma proximidade com o mundo real, assim como mais eficiente na sua prática diária.

As bibliotecas e centros de leitura seguem recomendações de construção física e devem ter os recursos audiovisuais, publicações em texto digital acessível e serviço de apoio, segundo a norma da ABNT NBR 9050, no item 10.16.5, correspondendo aos pedidos dos usuários que o conteúdo digital auxilie no acesso físico da Biblioteca Central da UFPB, reduzindo o tempo de procura pelos itens (ABNT, 2020). Para Choo (2003, p. 118), "as necessidades de informação não surgem plenamente formadas, mas são clarificadas e definidas durante um período de tempo". Isso implica no conhecimento das necessidades dos usuários no planejamento e desenvolvimento dos portais da UFPB.

Os entrevistados E1, E2, E3 relataram que o sistema não dispõe de uma interface adaptada para que sejam, facilmente, encontradas as páginas consultadas e o retorno para as visitadas. O E1 afirmou que: "só consigo realizar o uso em sua totalidade pois uso a aba do navegador para encontrar o ponto de partida, além de possuir programas como Dosvox no computador de mesa e Talback no celular, que faz a leitura dos textos, reduzindo minha dificuldade de leitura". Já o E2 e E3 que compreendem o português, já sentem a dificuldade pelo próprio sistema, como diz o E2: "no próprio site não consigo essa 
possibilidade de retorno ao ponto anterior, fico perdida na busca". Nesse sentido, foram relatados o SIGAA e o site da Biblioteca Central da UFPB, como exemplos de dificuldades na busca pela informação, pois sua estrutura não permite 0 retorno adequado às outras interfaces.

De acordo com os entrevistados E4 e E5, as dificuldades com a ausência de elementos na interface dos sistemas estão relacionadas com aqueles que não possuem linguagem Braille. Ou seja, para o usar o SIGAA e portais da UFPB os entrevistados só têm acesso através dos intérpretes. O entrevistado E6 relatou que: "os sistemas por não possuírem a linguagem principal deles (Braille.), torna-se totalmente complicado compreender a execução do sistema". Segundo o Estatuto da Pessoa com Deficiência,

$\S 2^{\circ}$ Consideram-se formatos acessíveis os arquivos digitais que possam ser reconhecidos e acessados por softwares leitores de telas ou outras tecnologias assistivas que vierem a substituí-los, permitindo leitura com voz sintetizada, ampliação de caracteres, diferentes contrastes e impressão em Braille (BRASIL, 2015, não paginado).

O uso de recurso com acessibilidade tem que sair da forma representativa de uma política de inclusão e se direcionar a uma prática de ação inclusiva, ocasionando satisfação aos seus usuários por meio de um sistema acessível. Nota-se então que, a ausência de uma linguagem comum que corresponda ao acesso às pessoas, assim como uma interface são fatores que comprometem a usabilidade dos sistemas acadêmicos.

\subsection{CATEgoria 2 - UsABILIDAde dos Sistemas ACAdÊMICos}

Nesta categoria, quatro heurísticas de Nielsen (1994) estão presentes na análise: usabilidade voltada para a liberdade de controle fácil para o usuário, a flexibilidade e eficiência de uso, a estética e design minimalista e o reconhecimento em vez de memorização.

As entrevistas realizadas enfatizaram que a usabilidade dos sistemas acadêmicos está, em sua maioria, relacionada à linguagem que se encontra nos portais. Ou seja, o "português" não é a primeira língua para os sujeitos da pesquisa, e sim o Braille. Nesse caminho, a liberdade e controle de uso são 
pontos fundamentais para o sujeito "E4", que relata de forma enfática: "gostaria de poder acessar os sistemas, sozinha e ter o controle de uso como todas as outras pessoas. Quero ter AUTONOMIA e acessar facilmente SEM PRECISAR DE NINGUÉM". Não tão indignado o E5 também relatou: "o uso de sistemas só é possível nos programas que possuem Braille e assim mesmo, infelizmente, somente estão instalados na sala do NEDESP - Núcleo de Educação Especial. Em outros laboratórios não possuem NDVA, DosVox. Porém, eles servem apenas para tradução e não estão relacionados aos sistemas acadêmicos da UFPB, como o SIGAA." Os entrevistados também realizaram críticas aos professores que levam filme para sala e não se lembram de que existem pessoas com deficiência visual.

Nessa perspectiva, o E1 evidenciou a falta dos vídeos em Braille, o que corresponde a uma barreira digital a ser enfrentada não só em sala de aula, mas nos portais da UFPB, necessitando o aluno ledor quando não tem o leitor de texto, já que o sistema não facilita a memorização das atividades executadas pelo usuário. O E2 relatou que: "a desatualização das informações dos sites da UFPB exige que o usuário remeta a outros sites de busca", não completando sua tarefa no mesmo site, apesar de ledora. E o E3 acrescentou: "desatualizado, difícil acessibilidade e compreensão quando se quer retornar há sempre uma dificuldade no caminho". Logo, essa condição desnecessária pode ser evitada pelo poder público, visto que,

Art. 69. O poder público deve assegurar a disponibilidade de informações corretas e claras sobre os diferentes produtos e serviços ofertados, por quaisquer meios de comunicação empregados, inclusive em ambiente virtual, contendo a especificação correta de quantidade, qualidade, características, composição e preço, bem como sobre os eventuais riscos à saúde e à segurança do consumidor com deficiência, em caso de sua utilização, aplicando-se, no que couber, os arts. 30 a 41 da Lei no 8.078, de 11 de setembro de 1990 (BRASIL, 2015, não paginado).

De acordo com Nielsen (1994), é natural que os usuários, com alguma frequência, acessem alguma função por engano, e por isso os sistemas precisam apresentar caminhos de saída ou retorno para o estado anterior. Assim, percebese que deverá ter acesso para retornar, apenas dos lugares que conseguimos, 
até por engano, acessar. O contrário, não.

$\mathrm{O} E 6$, se posicionou de forma enfática dizendo que se houvesse a linguagem Braille nos sistemas, daria a acessibilidade a todos que necessitam o seu uso. Assim ele desabafou: "como usar sistemas acadêmicas que não possuem nossa língua, Braille? Como um discente ou docente que precisa ter acesso as suas notas, materiais, biblioteca digital não tem recursos no SIGAA? A primeira língua nos sistemas é portuguesa e nós não sabemos!"

Quanto ao costume de acessar, uma parte dos entrevistados disse que tenta em casa com ajuda de alguém. Já outros se posicionaram alegando que o acesso só se dá no laboratório do NEDESP com ajuda de seu intérprete. O E4 se posicionou insatisfeito com a limitação de local e independência: "queria poder acessar em qualquer local e ter liberdade de não precisar de ninguém".

Para alguns, o uso no computador do leitor de texto no computador, NDVA, Dox Vox, ajuda muito, mas só está disponível no NEDESP. O talkback, recurso de acessibilidade do Android ajuda porque lê os menus e texto da tela em voz alta, facilitando o uso do aparelho por pessoas com problemas de visão. Nesse contexto, o artigo $3^{\circ}$ da Lei 13.146 prevê que "o poder público deve estimular e apoiar a adaptação e a produção de artigos científicos em formato acessível, inclusive em Libras" (BRASIL, 2015, não paginado).

Corroborando com a Lei 13.146, Nielsen (1994, p. 16) alega que "o sistema deve ser eficiente na tarefa que se propõe a realizar. $O$ usuário deve atingir um alto nível de produtividade". Porém, para que a usabilidade dos sistemas seja eficiente, os entrevistados relataram que os conteúdos dos sites da UFPB não são intuitivos e nem fáceis para os usuários e recorrerem ao Google em busca de tutoriais. Muitas vezes a busca e a compreensão do conteúdo se inicia no Google, caso não resolva, se consulta o site da UFPB. Para os entrevistados E2 e E3, as "informações estão escondidas".

Em relação às orientações para uso, auxílios e suporte, assim como padrões e recuperação de erros, a categoria a seguir relatará as percepções dos entrevistados. 


\subsection{Categoria 3 - Padrões, Prevenção e Ajuda}

Nesta categoria, quatro heurísticas de Nielsen (1994) estão presentes na análise: Consistência e padrões, prevenção de erros, ajuda os usuários a reconhecerem, diagnosticarem e recuperarem-se de erros, ajuda e documentação.

Nesta categoria de análise, os entrevistados demostraram claramente que não estão satisfeitos com a quantidade de barreiras digitais nos sistemas acadêmicos. Assim, eles evidenciam a ausência de ajuda, inconsistência de padrões e prevenções de erros. Para eles, tem que melhorar muito a acessibilidade para atender às suas necessidades com os recursos adequados nos sistemas. O E1 relata de forma enfática: "a interface não ajuda a gente usar". No mesmo caminho os demais responderam e listaram as seguintes barreiras digitais no acesso aos sistemas: Ausência de laboratórios com sistemas em Braille; Professor com aulas que contêm sistemas que eles não têm condições de acesso; Ausência de sistemas com leitores de voz; Falta de atualização de informações nos bancos de dados para facilitar a busca por informações, por exemplo, não tem todas as informações necessárias para identificar os servidores com necessidades especiais; o SIGAA não possui recurso para a língua Braille.

Nesses aspectos, de acordo com Ferreira (2007) poderia existir um processo avaliativo do uso para que se tenha um diagnóstico da eficiência do sistema. Logo, seria possível monitorar e solucionar as barreiras digitais de forma contínua, evitando exclusões.

Para apenas um entrevistado, com baixa visão, o SIGAA não mostra com clareza a atividade disponibilizada pelo professor, assim como é difícil baixar o arquivo em pdf. Dispor de um sistema e não oferecer capacitação e acesso não é admitir a acessibilidade. É preciso ter a adaptabilidade de acordo com as necessidades e demandas dos usuários da UFPB nas diversas categorias de deficiências, transpondo o grau, nível e intensidade das suas necessidades (DIAS; PIRES, 2004). Da mesma forma, é também difícil de acessar as informações, devido ter que abrir várias abas no portal, sem documento de 
orientação de uso. Para Nielsen (1994), os sistemas precisam ser acessados sem o uso de manuais. Entretanto, caso precise é necessário existir documentação e suporte para orientação do uso.

De acordo com Barros, Saorim e Ramalho (2008), as necessidades dos usuários se relacionam com incertezas e angústias. Logo, percebe-se que os entrevistados buscam soluções para sanar essas necessidades no uso rotineiro e acesso aos sistemas acadêmicos.

\subsection{INCIDENTE CrítICO}

Refletindo sobre seu uso rotineiro no acesso aos sistemas, o incidente crítico corresponde à última situação ocorrida com o usuário nas suas necessidades, busca e uso de informação. Assim, os entrevistados relataram, de forma quase unânime que perceberam isso, quando necessitaram acessar o SIGAA para verificar notas, faltas, conteúdos e estrutura curricular. As dificuldades se direcionaram, em sua maioria (5 de um total de 6 entrevistados) para uma linguagem em Braille a dependência de um intérprete para o acesso. Salienta-se que, a exceção se deu apenas em um entrevistado, já que sua deficiência não é visual e nem auditiva e sim, física.

Nota-se então que, as dificuldades encontradas se relacionam com necessidades contínuas que um usuário de um sistema acadêmico possui em sua rotina, o que se torna uma barreira digital em um processo extremamente preocupante. Assim os entrevistados, como usuários que enfrentam barreiras digitais na rotina de busca informações, relacionaram sugestões e melhorias, como seguem listados no próximo tópico.

\section{SUGESTÕES DE MELHORIAS PARA PROPORCIONAR UMA USABILIDADE E ACESSIBILIDADE EFICAZES NOS SISTEMAS ACADÊMICOS}

Diante dos relatos dos entrevistados, tanto docentes quanto discentes, todos eles se posicionaram com sugestões para melhorias para a acessibilidade 
e usabilidade dos sistemas, que eles consideraram necessárias em suas vidas acadêmicas. Entretanto, em desabafos eles consideraram que é preciso ter um posicionamento mais direcionado da instituição, de forma inclusiva, para atender e solucionar as barreiras digitais. Assim as melhorias, para todos, seguem a mesma direção de necessidade, conforme listado a seguir:

$\checkmark$ O SIGAA deveria ter recursos para dar acesso a todos os discentes e docentes, sem excluir nenhum tipo de deficiência;

$\checkmark$ Todos os sistemas deveriam ter o Braille, além do português;

$\checkmark$ O Portal de Periódico da CAPES deveria conter ferramentas para acessibilidade;

Sites deveriam permitir a leitura pelo leitor de texto, sem necessidade do aluno leitor;

$\checkmark$ Melhorar o contraste do site, pois os coloridos não são possíveis de leitura. As cores preta e azul são as melhores para se ler, ou senão, tem que aumentar a letra do texto;

$\checkmark \quad$ Atualização dos bancos de dados para facilitar a busca nas interfaces dos sites, por exemplo, o Portal da UFPB;

$\checkmark \quad$ O site da Biblioteca Central da UFPB poderia disponibilizar notícias com os serviços virtuais oferecidos pela UFPB e como acessá-los, exemplo os repositórios;

$\checkmark$ A biblioteca Central da UFPB poderia oferecer a produção acadêmica na linguagem dos sinais - Libras.

Percebe-se que as sugestões listadas pelos entrevistados demonstram de forma clara o quanto a usabilidade e a acessibilidade nos sistemas de informações estão ainda distantes das suas necessidades de informação, ocasionando barreiras digitais aos usuários especiais.

\section{CONSIDERAÇÕES FINAIS}

A realização da pesquisa teve como objetivo analisar a acessibilidade digital pelos usuários de informação nos sistemas acadêmicos na UFPB. Com a análise de dados, percebeu-se, com clareza que uma linguagem comum é um 
ponto de barreira digital no acesso para todos, sendo algo extremamente comprometedor porque é a forma de leitura dos usuários nos conteúdos disponibilizados nos sistemas acadêmicos. Para os entrevistados na pesquisa, a linguagem ofertada nos ambientes é como uma linguagem estrangeira. Logo, é impossível ter uma autonomia de acesso e uso.

Os resultados da pesquisa também demonstraram que sendo a interface um sistema que corresponde ao elo entre ela e os usuários, diversos problemas de usabilidade podem ocorrer, mas precisam ser resolvidos através de uma melhoria na disponibilidade de recursos, evitando assim barreiras digitais. É preciso, ainda, ficar sempre atento a todas as barreiras, que podem ir além das tecnológicas. De acordo com Bellini et al. (2012), as limitações estão além das Tecnologias da Informação e Comunicação.

$\mathrm{Na}$ análise dos dados foram obtidos relatos que identificaram diversas barreiras digitais de usabilidade dos sistemas como: dificuldades para realização de navegação nos sistemas; Ausência de uma linguagem de acesso para todos; impossibilidade de localização das informações desejadas; dificuldades na utilização das ferramentas disponíveis nas interfaces; interfaces pouco intuitivas, demandando muito conhecimento dos usuários.

Com esses resultados foi possível identificar um alto índice de insatisfação dos usuários com a utilização dos sistemas analisados. Essa realidade é muito prejudicial para a sociedade acadêmica, pois, a insatisfação com a utilização dos sistemas resulta na rejeição e, com isso, a falta de incentivo para o desenvolvimento de melhorias nesses sistemas através do desenvolvimento de novas funcionalidades.

Correlacionando os resultados da pesquisa ao que as dez heurísticas de Nielsen recomendam para melhorias na usabilidade de sistemas de informação, eles se contrapõem diante das barreiras digitais relatadas pelos entrevistados. As barreiras relatadas pelos usuários se prenderam a três das heurísticas de Nielsen: "Liberdade de controle fácil para o usuário", "Flexibilidade e eficiência de uso" e "Correspondência entre o sistema e o mundo real". Como comentou o entrevistado E4: "precisamos de ter autonomia para acessar e usar os sistemas sem precisar depender de intérpretes, como todos as demais pessoas que não 
possuem deficiência. Precisamos dos sistemas da mesma forma e intensidade dos demais discentes e docentes".

Diante do exposto é oportuno propor a realização de um maior investimento nas interfaces dos sistemas acadêmicos na busca de melhorias na usabilidade e acessibilidade com linguagens disponíveis para todos, e que essas melhorias tenham base nas heurísticas de Nielsen (1994). É preciso enfatizar a importância de uma avaliação contínua na busca de melhorias na acessibilidade digital para evitar barreiras e comprometimento à vida acadêmica de discentes e docentes, especialmente dos portadores de necessidades especiais.

Salienta-se ainda que, ao término da pesquisa foram alcançados os resultados e soluções originadas dos próprios sujeitos.

\section{FINANCIAMENTO}

O presente trabalho foi realizado com apoio da Coordenação de Aperfeiçoamento de Pessoal de Nível Superior - Brasil (CAPES), código de financiamento 001.

\section{REFERÊNCIAS}

ASSOCIAÇÃO BRASILEIRA DE NORMAS TÉCNICAS. ABNT NBR 9050:

Acessibilidade a edificações, mobiliário, espaços e equipamentos urbanos. Rio de Janeiro: ABNT, 2015. 148 p. Disponível em:

http://www.portaldeacessibilidade.rs.gov.br/uploads/1596842151Emenda_1_AB NT_NBR_9050_em_03_de_agosto_de_2020.pdf. Acesso em: 01 dez. 2019.

ASSOCIAÇÃO BRASILEIRA DE NORMAS TÉCNICAS. ABNT NBR 9050:

Acessibilidade a edificações, mobiliário, espaços e equipamentos urbanos. 4.ed. Rio de Janeiro: ABNT, 2020. 147 p. Disponível em:

https://www.caurn.gov.br/wp-content/uploads/2020/08/ABNT-NBR-9050-15Acessibilidade-emenda-1_-03-08-2020.pdf Acesso em: 11 mar. 2021.

BARBOSA, A. E. V. Abordagem híbrida para a avaliação de interfaces multimodais. 2009. 346 f. Dissertação (Mestrado em Ciência da Computação) - Centro de Engenharia Elétrica, Universidade Federal de Campina Grande, Campina Grande, 2009.

BARROS, Dirlene Santos; SAORIM, Roberto Natal Silva; RAMALHO, Francisca Arruda. Necessidades informacionais e comportamento de busca da 
informação dos vereadores da câmara municipal de João Pessoa - Paraiba. Informações \& Sociedade: Estudos dos periódicos -UFPB., João Pessoa, v.18, n.3, p. 171-184, set./dez. 2008. Disponível em https://www.brapci.inf.br/_repositorio/2010/10/pdf_d04d1a6cfc_0012332.pdf. Acesso em: Acesso em: $01 \mathrm{dez} .2019$.

BARDIN, Laurence. Análise de conteúdo. Lisboa: Edições 70, 2016.

BELLINI, C. G. P.; ISONI FILHO, M. M.; GARCIA, D. de A.; PEREIRA, R. de C. de F. Limitações digitais: evidências teóricas preliminares. Revista Análise, Porto Alegre, v. 23, n. 1, p. 58-70, jan./abr. 2012.

BRASIL. Departamento de Governo Eletrônico. EMAG: Modelo de Acessibilidade em Governo Eletrônico. 2014. Disponível em: http://emag.governoeletronico.gov.br/. Acesso em: 01 dez. 2019.

BRASIL. Lei o 13.146, de 06 de julho de 2015. Institui a Lei Brasileira de Inclusão da Pessoa com Deficiência. Lei Brasileira de Inclusão da Pessoa Com Deficiência: Estatuto da Pessoa com Deficiência. Brasília, DF: DOU, 06 jul. 2015. Disponível em: http://www.planalto.gov.br/ccivil_03/_Ato20152018/2015/Lei/L13146.htm. Acesso em: 01 dez. 2019.

CHOO, C. W. Como ficamos sabendo - um modelo de uso da informação. In: $\mathrm{CHOO}, \mathrm{C}$. W. A organização do conhecimento: como as organizações usam a informação para criar significados, construir conhecimento e tomar decisões. São Paulo: Senac, 2003, p. 63- 120.

DIAS, Maria Matilde; PIRES, Daniela. Usos e usuários da informação. São Carlos: Edufscar, 2004.

FLANAGAN, J. C. A técnica do incidente crítico. Arquivos Brasileiros de Psicologia Aplicada, Rio de Janeiro, v. 25, n. 2, p. 99-141, abr./jun. 1973.

FERREIRA, D. S. Abordagem Híbrida para Avaliação da usabilidade de Dispositivos Móveis. 2007. 227 f. Dissertação (Mestrado em Informática) Centro de Engenharia Elétrica e Informática, Universidade Federal de Campina Grande, Campina Grande, 2007.

FERREIRA, S. M. S. P. Estudos e necessidades de informação: dos paradigmas tradicionais à abordagem Sense-Making. Porto Alegre: [s.n], 1997.

FIGUEIREDO, N. M. Paradigmas modernos da Ciência da Informação. São Paulo: Polis/APB, 1999.

FUCUSHIMA, A. A.; MARQUES, A. P. A. Z.; PARRÃO, J. A. O. Revisão da literatura sobre usabilidade e acessibilidade em ambiente web. EtiC: encontro 
de iniciação científica, Presidente Prudente, v. 16, n. 16, 2020. p. 1-15. Disponível em:

http://intertemas.toledoprudente.edu.br/index.php/ETIC/article/view/8604. Acesso em: 06 out. 2020.

GUINCHAT, C.; MENOU, M. Usuários. In: GUINCHAT, C.; MENOU, M. Introdução geral às técnicas da informação e da documentação. Brasília, D.F.: IBICT, 1994. p. 481-491.

HENRY, S. L. (Ed.). W3C. Introduction to Web Accessibility. 2019. Disponível em: https://www.w3.org/WAl/fundamentals/accessibility-intro/. Acesso em: 01 dez. 2019.

HOTT, D. F. M.; CRUZ-RIASCOS, S. A. Ciência da informação e interações teórico-sistêmicas com a acessibilidade. In: ENCONTRO NACIONAL DE PESQUISA EM CIÊNCIA DA INFORMAÇÃO, 19., 2018, Londrina. Anais [...] Londrina, 2019. Disponível em: brapci.inf.br/index.php/res/download/121810. Acesso em: 12 nov. 2019.

NIELSEN, J. Usability engineering. San Diego: Academic Press, 1994.

PASSERINO, L. M.; MONTARDO, S. P. Inclusão social via acessibilidade digital: proposta de inclusão digital para pessoas com necessidades especiais. E-compós: revista da Associação Nacional dos Programas de Pós-Graduação em Comunicação, v. 8, p. 1-18, abr. 2007.

PRODANOV, C. C.; FREITAS, E. C. Metodologia do Trabalho Científico: métodos e técnicas da pesquisa e do trabalho acadêmico. 2. ed. Novo Hamburgo: Feevale, 2013.

QUEIROZ, J. E. R. Abordagem híbrida para a avaliação da usabilidade de interfaces com o usuário. 2001. $410 \mathrm{f}$. Tese (Doutorado em Engenharia Eletrica) -Centro de Engenharia Elétrica e Informática, Universidade Federal da Paraíba, Campina Grande, 2001.

SARACEVIC, T. Ciência da informação: origem, evolução e relações.

Perspectivas em Ciência da Informação, Belo Horizonte, v. 1, n. 1, p. 41-62, jan./jun. 1996.

SANTOS, J. C. A.; VIEIRA, R. G. T.; CALDEIRA, G. C.; MARQUES, A. P. Z. Acessibilidade na Web: proporcionando inclusão e derrubando barreiras. EtiC: encontro de iniciação científica, Presidente Prudente, v. 14, n. 14, 2018. Disponível em: http://intertemas.toledoprudente.edu.br/index.php/ETIC/article/view/7217. Acesso em: 06 out. 2020.

SOUZA, E. R. Acessibilidade web: diferentes definições e sua relação com o design universal. Diálogo com a Economia Criativa, Rio de Janeiro, v. 1, n. 1, 
p. 13-28, 2016. Disponível em: http://dialogo.espm.br/index.php/revistadcecrj/article/view/33. Acesso em: 06 de out. 2020.

UNIVERSIDADE FEDERAL DA PARAÍBA. Centro de Educação (CE). Núcleo de Educação Especial (Nedesp). 2018. Disponível em: http://www.ce.ufpb.br/nedesp. Acesso em: 20 nov. 2019.

UNIVERSIDADE FEDERAL DA PARAÍBA. Comitê de Inclusão e Acessibilidade (CIA). Comitê de Inclusão e Acessibilidade (CIA). 2018. Disponível em: http://www.ufpb.br/cia. Acesso em: 20 nov. 2019.

VIDOTTI, S. A. B. G.; ROA-MARTÍNEZ, S. M.; CONEGLIAN, C. S.; FERREIRA, A. M. J. F. C.; VECHIATO, F. L. As contribuições das heurísticas de usabilidade para encontrabilidade da informação. In: ENCONTRO NACIONAL DE PESQUISA EM CIÊNCIA DA INFORMAÇÃO, 18., 2017. Anais [...], Marília, 2017. Disponível em:

https://brapci.inf.br/_repositorio/2017/10/pdf_d29e8b00e7_0000027159.pdf. Acesso em: 03 dez. 2019.

\title{
DIGITAL ACCESSIBILITY IN ACADEMIC SYSTEMS AT UFPB: ANALYZE FROM USABILITY HEURISTICS
}

\begin{abstract}
Introduction: Digital accessibility - a theme that needs reflection - has challenges in the face of barriers, sometimes explicit or not for users of information. Objective: In this context, the aim of this study is to analyze the digital accessibility in academic systems at Federal University of Paraíba (UFPB) from usability heuristics. Methodology: In the methodological procedures, the research is characterized as exploratory and qualitative in nature. As a data collection instrument, a semi-structured interview was adopted, which was applied to UFPB students who are part of the Inclusion and Accessibility Committee of the Federal University of Paraíba and teachers who have some disability. For data analysis, Bardin's content analysis technique was used. Results:The survey results showed a high level of user dissatisfaction with the use of the systems in aspects involving "freedom of easy control for the user", "flexibility and efficiency of use" and "correspondence between the system and the real world" that correspond to factors of great digital barriers, with emphasis on the absence of a common language and inadequate interface. Conclusion: It is concluded, then, that the academic portals of UFPB do not offer accessibility and present digital barriers compromising the academic life of students and teachers in their information needs. Falta introdução no resumo
\end{abstract}

Descriptors: Digital accessibility. Academic Systems. Usability. Information Barriers. User of Information.

\section{APRESENTAR O TÍTULO EM ESPANHOL (PARA TEXTOS EM PORTUGUÊS E INGLÊS).}




\title{
ACCESIBILIDAD DIGITAL EN SISTEMAS ACADÉMICOS DE UFPB: ANÁLISIS DESDE LA USABILIDAD HEURÍSTICA
}

\begin{abstract}
RESUMEN
Introducción: La accesibilidad digital, un tema que necesita reflexión, presenta desafíos frente a barreras, a veces explícitas o no para los usuarios de la información. Objetivo: En este contexto, el objetivo de este estudio es analizar la accesibilidad digital en los sistemas académicos de la Universidad Federal de Paraíba (UFPB) a partir de heurísticas de usabilidad. Metodología: En los procedimientos metodológicos, la investigación se caracteriza por ser de carácter exploratorio y cualitativo. Como instrumento de recolección de datos se adoptó una entrevista semiestructurada, la cual se aplicó a estudiantes de la UFPB que forman parte del Comité de Inclusión y Accesibilidad de la Universidad Federal de Paraíba y docentes que presentan alguna discapacidad. Para el análisis de datos se utilizó la técnica de análisis de contenido de Bardin. Resultados: Los resultados de la encuesta mostraron un alto nivel de insatisfacción del usuario con el uso de los sistemas en aspectos que involucran "libertad de fácil control para el usuario", "flexibilidad y eficiencia de uso" y "correspondencia entre el sistema y el mundo real" que corresponden a factores de grandes barreras digitales, con énfasis en la ausencia de un lenguaje común y una interfaz inadecuada. Conclusiones: Se concluye, entonces, que los portales académicos de la UFPB no ofrecen accesibilidad y presentan barreras digitales comprometiendo la vida académica de estudiantes y docentes en sus necesidades de información.
\end{abstract}

Descriptores: Accesibilidad digital. Sistemas académicos. Usabilidad. Barreras a la información. Usuario de información.

Recebido em: 05.05.2020

Aceito em: 13.12.2020 